\title{
Uma proposta para a análise da identidade de marca dos canais de televisão brasileiros
}

\author{
Adriano Sampaio*
}

\begin{abstract}
RESUMO
A proposta metodológica apresentada neste artigo pretende oferecer instrumentos para observar como são construidas as estratégias de distinçāo utilizadas pelos canais de televisão brasileiros, pois cada canal de comunicação quer se diferenciar dos demais em um cenário de concorrência. Desse modo, as emissoras se constituem como enunciadores, sendo dotadas de um ponto de vista, e responsáveis por aquilo que dizem. Este posicionamento discursivo, das emissoras, interfere na arena de disputa da esfera pública midiática. Este estudo é produto de uma pesquisa de doutorado, em andamento, que pretende identificar a identidade de marca de dois canais de televisão brasileiros: A TV Globo e a TV Record. A démarche escolhida é a anàlise do discurso da informação destas duas emissoras. Para tanto, almeja-se observar as estratégias de distinção utilizadas pelos dois canais de televisão, em referência, quando veiculam seus telejornais lideres de audiência no horário nobre: Jornal Nacional e Jornal da Record.

Palavras-chaves: Identidade de marca. Televisão. Telejornal
\end{abstract}

\section{ABSTRACT}

The proposal methodological presented in this article intends to offer parameters to observe the strategies of distinction that are developed by the Brazilians' television channels, therefore, each TV channel wants to make difference against their concurrence. In this way, the channels could be understood as enunciators, and they have a point-of-view. In this way, they have a social responsibility for what they say and the discourse produced by these actors intervenes in the public sphere. This study is a product of a doctoral research, in progress, that intends to identify two Brazilians' television channels' image of mark: TV Globo and TV Record. The corpus chosen is the discursive analysis of the news discourse of these two TV channels. For in such a way, it intends to observe the strategies of distinction used by the two television channels in reference when they broadcast its TV-News leaders of audience, in prime time: The TV-News Jornal Nacional and Jornal da Record.

Keywords: Image of mark. Television. TV-News

\footnotetext{
- Doutorando do Programa de Pós-Graduação em Comunicação e Cultura Contemporâneas da Universidade Federal da Bahia (POSCOM/UFBA). Integrante do grupo de pesquisa de Análise de Telejornais, coordenado pela Prof.a. Dr.a ltania Maria Mota Gomes, orientadora da pesquisa em referência. Atualmente, realiza estágio-doutoral na Universidade de Paris III, Sorbonne Nouvelle, sob a orientação do Prof. Dr. François JOST.
} 


\section{Introdução}

Há nos estudos sobre televisão uma abordagem, que aqui se denomina mídia generalista, na qual o termo "mídia" é empregado como um conjunto de todos os dispositivos midiáticos. Nessa perspectiva, fazem-se julgamentos, tais quais: a mídia manipula, a mídia cria necessidades, não havendo espaço, entretanto, para a discussão sobre as particularidades de cada dispositivo (televisão, rádio, jornal etc), bem como as diferenças que existem entre os diversos enunciadores que estão presentes no espaço público midiático: canais de televisão privados $\mathrm{x}$ públicos, revistas femininas, jornais impressos, entre outros. Também não é oferecida muita atenção às particularidades culturais de cada país no qual se encontram estes suportes.

Em um segundo tipo de abordagem, que para os fins deste trabalho denomina-se mídia não-generalista. Estão aqueles que acreditam em uma variação dos discursos midiáticos. Tanto no que concerne a diferença entre os distintos suportes, bem como entre os

94 diversos enunciadores (revistas, jornais, programas de televisão). Dentro desta abordagem estão os autores que utilizam a noção de contrato, mais especificamente, Eliseo Verón (1985) e o seu contrato de leitura, seu principal expoente. Diferente da primeira abordagem mencionada, os autores que defendem uma mídia não-generalista identificam uma distinção entre os diversos suportes (rádio, tv, jornais etc) e os diversos enunciadores. Contudo, limitam-se ao plano da enunciação, pois tomam como pressuposto que a distinção entre os suportes midiáticos não está no plano do enunciado (do conteúdo), mas apenas nas maneiras de dizer, isto é, no âmbito da enunciação.

Os estudos do contrato de leitura que têm como finalidade descrever o plano da enunciação, apresentam que muitas vezes, dois suportes extremamente parecidos do ponto de vista de suas editorias e dos seus conteúdos, são em verdade muito diferentes um do outro sob o plano do contrato de leitura. (tradução nossa)(VERÓN, 1985, p.209).

Cada uma das duas correntes apresentadas, até então, dispõem de forças e fraquezas. A primeira, denominada aqui mídia generalista, consegue mapear e descrever as interferências políticas, culturais e sociais dos dispositivos midiáticos na sociedade, contudo suas 
análises não contemplam as particularidades de cada suporte ou canal de comunicação e tratam a mídia como se fosse um somatório de um discurso hegemônico e homogêneo. Esta perspectiva, não consegue identificar, deste modo, as particularidades de cada suporte e observar o cenário de disputa que é uma das principais características do espaço público midiático.

A segunda abordagem, midia-não generalista, por sua vez, respeita as heterogeneidades do discurso midiático e identifica as arenas de disputa presentes entre os suportes. Contudo, essa abordagem não problematiza a interferência dos veículos como responsáveis pelo seu discurso, pois minimizam a ordem do dito e acreditam em uma homogeneidade dos discursos midiáticos sob o plano dos enunciados. Desse modo, menosprezam as implicações dos atos de fala destes enunciadores no espaço público.

O presente trabalho propõe uma terceira via de observação que considera como premissa: 1 . os atos de fala dos diversos enunciadores midiáticos interferem na sociedade e 2. É a pluralidade de pontos de vista (conteúdo) e de maneiras de dizer (enunciação) que constituem o discurso midiático na esfera pública. Assim, cada canal de comunicação ou periódico quer se diferenciar dos demais em um cenário de concorrência (HARTLEY, 2001). Desse modo compreendido, cada canal de televisão ou periódico se apresenta para o seu público e são responsáveis pelo que dizem. Eles se constituem como enunciadores (JOST, 1998; 1999) e são dotadas de um 'ponto de vista' (JOST, 1998). Este posicionamento discursivo interfere na discussão pública e na arena de disputa midiática.

Há uma identidade de marca para cada canal de televisão, e a proporção que este laço se torna mais forte com o seu público, maiores são os índices de audiência. Pretende-se observar como esta relação, entre canais de televisão e audiência, é construida. Contudo, é sabido que este problema é complexo e engloba diversas variáveis. Para tanto, torna-se preciso delimitar um lugar de estudo para esta problemática.

\section{Como delimitar esta análise?}

O modo de funcionamento dos canais de televisão, no Brasil, tem como estrutura, no que concerne à produção de conteúdo, três grandes departamentos: jornalismo, entretenimento e teledramaturgia (ficção). Há inúmeros diretores em cada núcleo de produção e a 
contratação e mudança de profissionais no interior das organizações, os canais de televisão, influenciam nos modos de produção dos seus núcleos de: jornalismo, entretenimento e ficção (teledramaturgia) ${ }^{1}$. Há, portanto, uma lógica de funcionamento própria dos canais de televisão de se apresentar em relação ao seu público a partir destas subdivisões: Jornalismo (mundo real), Entretenimento (mundo lúdico) e Teledramaturgia (mundo da ficção).

Segundo as discussões propostas sobre a Paleotelevisão e a Neotelevisão por Umberto Eco (1983), Francesco Caseti e Roger Odin (1990) e François Jost (1998), a televisão pode ser compreendida, em síntese, a partir destas três estruturas. 1. Informação (mundo real), 2. Ficção (mundo fictício) e 3. Fantásia (mundo lúdico). E os seus programas transitam entre estes três "mundos". Ora se aproxima mais de um, ora estão mais perto dos outros. Assim, há uma relação de aproximação entre a perspectiva teórica apresentada pelos autores mencionados, e a lógica de produção dos canais de televisão brasileiros: Departamento de Jornalismo (discurso da informação/ mundo real), Departamento de Entretenimento (mundo lúdico) e Núcleos de Teledramaturgia (mundo fictício).

\section{A identidade de marca e as estratégias de distinção dos canais de televisão.}

O estudo sobre a identidade de marca dos produtos midiáticos é objeto de estudo de diversos semioticistas, a exemplo de Andrea Semprine (1995) e Jean-Marie Floch (1990, 1985, 1984). Esta problemática está também presente nos trabalhos de Eliseo Verón (1985), na sua proposta do contrato de leitura, e também é objeto de interesse de François Jost $(2004,1999,1998)$ no seu modelo da promessa. Segundo Andrea Semprini (1994):

(...) há três propriedades que desde o momento em que o indivíduo ou o público as reconhece em uma marca buscam uma adesão, a mesma, com muita força e com maior facilidade; trata-se da credibilidade, legitimidade e sedução (tradução nossa) (SEMPRINI, 1992, p.70). 
Para este autor, estes três conceitos orientam a identidade de marca de diversos produtos, a exemplo, dos produtos de cosméticos e das marcas conhecidas em todo o mundo, a exemplo da Benetton. JeanMarie Floch utiliza principios similares para observar as estratégias de distinção que outros tipos de produtos fazem em relação ao seu público. Este autor apresenta uma observação das estratégias de distinção e fidelização desenvolvidas pelo jornal Daily Star em relação ao seu leitor (FLOCH, 1985). Em relação à perspectiva de análise das identidades de marca dos canais de televisão, François Jost (1999) afirma que:

Progressivamente os canais de TV são dotados de uma identidade pessoal, que para o espectador são, certamente, parcerias [...] para orientar esta interpretação, os canais recorrem a outras formas de comunicação, nomeada gêneros, dossiês de imprensa ou chamadas ${ }^{2}$. A confrontação do ato promissivo do canal de tv e da interpretação passam através de uma exploração de sua interface, o gênero [...] (JOST, 1999, p.20).

A proposta metodológica apresentada por este artigo pretende observar, analiticamente, como são construidas as estratégias de distinção utilizadas pelos canais de televisão com a finalidade de fidelizar a sua audiência no espaço público midiático brasileiro. Entretanto, para a efetivação de tal proposta é preciso desenvolver uma delimitação da problemática, uma vez que suas formas de funcionamento são complexas.

A primeira hipótese desta proposta, portanto, é que a identidade da marca do canal de televisão está subdividida nestes três mundos, já mencionados (Jornalismo/mundo real, Entretenimento/ mundo lúdico e Teledramaturgia/mundo da fiç̧ão). Assim, existe uma identidade da marca (IC) do canal presente no discurso da informação/ mundo real (IR); uma identidade da marca no mundo lúdico (IL); e no mundo da ficção (IF). Deste modo, a identidade da marca do canal de televisão é igual ao somatório das identidades de marca presentes nos outros mundos $(I C=I R+I L+I F)$.

Esta proposta pretende compreender a promessa de distinção que um canal de televisão faz em relação a sua audiência tomando como parâmetro que o ato promissivo do canal de tv e da sua 
interpretação são possíveis graças a uma exploração do gểnero dos programas que funcionam como uma interface. (JOST, 1999). Dito isso, a segunda hipótese levantada pelo trabalho é que os "gêneros mais puros" de cada úm dos três mundos (Informação, Fiç̧ão e Fantasia) expressam as estratégias que cada canal de televisão utiliza para se distinguir da sua concorrência. Assim, o "gênero puro" do discurso da informação é o telejornal; o gênero do discurso da ficção são as séries, no caso do Brasil as telenovelas; enquanto o "gênero puro" do mundo lúdico são os programas de jogos (ou de auditório) (JOST, 1999).

Outro fato importante é observar os dados de audiência dos programas. No Brasil, estes gêneros que aqui se denominam puros, por apresentarem menos hibridizações, são também os programas de maior audiência: o telejornal das $20 \mathrm{~h}$, as telenovelas e os programas de auditório. Por conseguinte, nestes programas são investidos os maiores recursos tanto simbólicos como materiais pelos canais de televisão.

\begin{tabular}{|c|c|c|c|c|}
\hline $\begin{array}{c}\text { Canal de televisão / } \\
\text { Programa }\end{array}$ & $\begin{array}{c}\text { Audiência domiciliar } \\
\%\end{array}$ & $\begin{array}{l}\text { Audiência domiciliar } \\
\qquad(000)\end{array}$ & $\begin{array}{c}\text { Audiéncia } \\
\text { individual \% }\end{array}$ & $\begin{array}{c}\text { Audiência } \\
\text { individual } \\
(000)\end{array}$ \\
\hline \multicolumn{5}{|l|}{ GLOBO } \\
\hline $\begin{array}{l}\text { Jornal Nacional } \\
\text { (telejornal 20h) }\end{array}$ & 33 & 1,844 & 15 & 2,622 \\
\hline $\begin{array}{l}\text { Novela IIl - Páginas } \\
\text { da Vida } \\
\text { ( telenovela) }\end{array}$ & 46 & 2,569 & 22 & 3,847 \\
\hline $\begin{array}{l}\text { Big Brother Brasil } \\
\text { (reality show) }\end{array}$ & 39 & 2,215 & 19 & 3,446 \\
\hline \multicolumn{5}{|l|}{ RECORD } \\
\hline $\begin{array}{l}\text { Jornal da Record } \\
\text { ( telejornal 20h) }\end{array}$ & 10 & 582 & 5 & 816 \\
\hline $\begin{array}{l}\text { Novela } 3 \text { - Vidas } \\
\text { Opostas } \\
\text { (telenovela) }\end{array}$ & 12 & 687 & 6 & 1,071 \\
\hline $\begin{array}{l}\text { Super Tela Not } \\
\text { ( filme) }\end{array}$ & 12 & 678 & 6 & 1,098 \\
\hline
\end{tabular}

A terceira, e última hipótese do trabalho, está em supor que o direcionamento das estratégias de distinção de cada um dos mundos televisivos é orientado pelos três conceitos postulados por Semprini (1992): Credibilidade, Sedução e Legitimação, pois eles estão presentes em todos os processos de distinção da identidade da marca. A este processo de interligação dos mundos sob as estratégias de distinção Propõe-se para analisar a identidade de marca do canal de televisão a 
se: circulo de estratégias de distinção do canal (conforme pode ser observado no gráfico a seguir).

\section{A proposta metodológica}

Para a análise das estratégias de distinção dos canais, é preciso observar como os programas constroem a sua credibilidade, legitimação e/ou sedução em relação a sua audiência, a partir dos respectivos "gêneros puros". Além de uma análise discursiva do programa, devem ser utilizados como dados secundários as análises das chamadas, os dossiês de imprensa, e da grade de programação dos canais, bem como a clipagem das notícias veiculadas pela crítica televisiva sobre os respectivos programas (jornal das $20 \mathrm{~h}$, séries, game-shows). Estes dados auxiliam na construção do contexto no qual o programa está inserido, contudo, não se constituem como dado primário de análise.

Entretanto, esta proposta é unilateral e apenas dá conta do modo como o canal de televisão se apresenta ao seu público. A esta instância denomina-se: 1. Instância de promessa de identidade da marca do canal de televisão (veja o gráfico a seguir). Faz-se, portanto, necessário estabelecer uma outra instância para dar conta dos processos de recepção da identidade de marca pelo público, a esta se denomina: 11. Instância de reconhecimento da identidade da marca do canal de televisão.

Supõe-se que para uma análise dos processos de reconhecimento dos públicos dos canais de televisão, seja preciso desenvolver outra metodologia de análise que contemple a elaboração e execução de entrevistas com "espectadores de carne e osso", através de técnicas como: survey, entrevistas em profundidade e/ou grupos focais, tal qual sugerem Verón (1985) e Floch $(1985,1990)$. Na instância de reconhecimento da identidade da marca do canal faz-se presente um conflito que deve ser solucionado a partir das análises das entrevistas. Pois se o canal faz uma promessa ao se público - através da sua identidade de marca presente em cada um dos três mundos (real, lúdico e fictício) - existe também a desconfiança (Quérré, 2005) por parte do seu público se haverá a efetivação desta promessa. Assim, se o canal de televisão faz uma promessa a sua audiência, existem três outras 
Propõe-se para analisar a identidade de marca do canal de televisão a comparação entre essas duas instâncias: I. Promessa e II. Reconhecimento. A esta proposta metodológica denomina-se: a identidade da marca do canal de televisão, para mais bem compreendêla observe a sua representação gráfica a seguir.

\section{Metodologia da proposta}

Para desenvolver a análise da Instância de promessa de identidade da marca do canal de televisão é preciso:

a) Escolher um mundo (real, fictício, lúdico) para compreender as estratégias de distinção da marca utilizados pelos canais de televisão em cada mundo. Para esta proposta o mundo escolhido é o real (JOST, 1999).

b) Fazer uma análise comparativa entre, no mínimo, dois programas televisivos de "gênero puro" (mundo real/ telejornal; mundo fictício/séries; mundo lúdico/ jogos) de duas emissoras concorrentes.

c) Analisar o círculo de estratégias de distinção do canal de televisão (credibilidade, sedução e/ou legitimação) como um quadro geral a fim de compreender a relação entre as estratégias de distinção utilizadas pelos canais e sua expressão na identidade de marca presente em cada um dos mundos.

Por que falar em credibilidade, sedução e legitimidade no discurso da informação (mundo real)?

Segundo Paul Ricouer (2007), a retórica é a disciplina mais antiga sobre o estudo da linguagem. Aristóteles a define como sendo: '(...) a arte do discurso humano, mais humano' (tradução nossa) (RICOUER, 2007, p.106). Assim, um primeiro critério da arte retórica está em saber que: 1. é orientado a uma platéia, 2. é orientada pelo jogo da argumentação, e 3. visa a persuasão. Esta última deve ser entendida como: 
Da arte da persuasão passa-se sem transição à arte de enganar. $\mathrm{O}$ acordo prévio sobre as idéias recebidas desliza para a trivialidade do preconceito; da arte do agradar passa-se àquela da sedução, que é a violência do discurso (tradução nossa). (RICOEUR, 2007, p.106).

Kallmeyer (1996) ao tratar da "retórica da fala" também adere a estes pressupostos já mencionados. Segundo esse autor, a abordagem retórica também está presente em qualquer forma de fala e também é regida sob três perspectivas: 1. um modo de gestão de faces (Ethos), 2. um tratamento dado em função de um fim prático (Logos) e 3. um tratamento correlativo dos afetos (Pathos).

A fala tal qual salienta Bakhtin (2002), é uma ponte lançada entre os interlocutores de um discurso. E toda a palavra entra, por sua vez, em uma arena de disputa com outras falas presentes no contexto social. Para fins desta proposta, entende-se o discurso da informação enquanto uma fala. Dito isso, é regido pela retórica e está imerso em uma arena de disputa: a arena de disputa do espaço público midiático.

Esta imagem funciona como pano de fundo para o estudo em questão. Sendo assim, a disputa dos distintos canais de televisão dentro de uma esfera pública mediatizada (arena de disputa da palavra) tem como lógica de funcionamento:

1. Ethos (a construção de um modo de enunciação particular em relação a sua audiência),

2. Logos (uma forma particular de construção do mundo real, seu conteúdo)e

3. Pathos (uma maneira especifica de construir uma relação de afeto com o seu público, através da sedução).

Assim, há no círculo das estratégias de distinção do canal de televisão (credibilidade, sedução e/ou legitimação), aqui proposto, uma característica que está presente em qualquer ato de fala: a sedução, a legitimação, e a credibilidade. Quando se fala em Ethos, Logos e Pathos, pode-se apreender, deste modo, uma observação sobre a enunciação (Ethos) e uma atenção à ordem do dito/conteúdo (Logos), enquanto no 
Pathos, a sedução, está presente na relação entre essas duas outras instâncias, mencionadas.

Dito isso, a proposta metodológica, do estudo em referência, pretende compreender a relação de concorrência existente entre dois programas midiáticos, Jornal da Record e o Jornal Nacional, a partir de uma perspectiva que observa a construção discursiva do enunciador no que diz respeito a sua maneira de dizer (enunciação) e na sua ordem do dito (enunciado/conteúdo).

Desse modo, não se está de acordo com o pressuposto de Verón (1985) quando afirma que os conteúdos dos suportes midiáticos são homogêneos. É preciso, pois, observar também a ordem do conteúdo porque "Ele está aqui, eu o vejo, ele me fala" Verón (1983). Verón apesar de dizer que o apresentador fala ao seu público, ainda neste texto, ele toma como pressuposto que os conteúdos midiáticos são homogêneos e observa, apenas, as maneiras de dizer (enunciação) dos programas televisivos. Entretanto, é válido ressaltar a precisa análise de Verón (1983) ao identificar a enunciação do telejornal em uma perspectiva tanto sincrônica, como diacrônica, no estudo citado.

\section{Lógica de funcionamento do discurso da informação (mundo real) e sua relação com a credibilidade, sedução e legitimação.}

As normas funcionamento do discurso da informação têm como base os critérios de noticiabilidade, toma-se aqui como referência Mauro Wolf (2007) e sua discussão sobre este assunto. Para fins deste trabalho, o discurso da informação é uma construção social (TUCHMAN, 2002; 1993) e está subdividido em duas lógicas de funcionamento:

\section{A) Critérios sobre o seu conteúdo}

- Grau e nível hierárquico dos indivíduos envolvidos no acontecimento noticiável,

- Impacto sobre a nação e sobre o interesse nacional,

- Quantidade de pessoas que o acontecimento envolve

- Relevância do acontecimento

- Ponto de vista 


\section{B) Critérios relacionados ao produto}

- Brevidade (sedução e objetividade)

- Ideologia da informação

- Novidade,

- Balanceamento (balance)

Destes critérios de noticiabilidade desenvolveram-se três grandes variáveis relacionadas à aproximação da lógica de funcionamento do discurso da informação (critérios de noticiabilidade) com o circulo de estratégias de distinção do canal (credibilidade, sedução e legitimação) quando aplicados aos telejornais das $20 \mathrm{~h}$.

\section{Ethos - estratégias de distinção do discurso da informação sob a credibilidade}

Nesta lógica do Ethos é preciso observar as estratégias de construção da distinção dos telejornais através da construção da sua credibilidade. É válido ressaltar que tal perspectiva está ancorada sob o plano da enunciação. Para observar esta relação foram desenvolvidas três variáveis inspiradas no modelo teórico proposto por Itania Gomes $(2003 ; 2005)^{\prime}$.

A análise do papel dos apresentadores (os porta-vozes do discurso do canal de televisão sob os acontecimentos que são noticia no país):

A TV Globo, no seu Jornal Nacional, aposta na credibilidade de William Bonner e Fátima Bernardes, os jornalistas-celebridades das emissoras. A TV Record quando aposta na contratação de jornalistas de respaldo no campo, demonstra uma proposta inicial de busca de status ao seu jornalismo.

A análise da autenticidade (capacidade de estar lá): a capacidade que o jornal tem de "estar onde a notícia acontece".

A TV Globo aposta neste recurso como estratégia de distinção do seu discurso da informação e demonstra também a capacidade técnica da emissora em comparação à concorrência. Este canal dispõe de correspondentes em diversos países a exemplo de Itália, Nova York e 
Londres. Como o Jornal da Record se posiciona em relação a esta potencialidade do $\mathrm{JN}$ em sua estratégia de distinção?

\section{A análise sobre a construção do discurso jornalistico:}

Como cada um dos telejornais cria as suas estratégias de distinção a partir da escolha por um modo de "fazer" jornalismo? A escolha por um dos modos de jornalismos (informação, opinião ou serviço) pode dizer do modo como o canal quer se distinguir em relação aos demais.

\section{Logos: estratégias de distinção do discurso da informação} sob a legitimação

Nesta lógica do Logos é preciso observar as estratégias de distinção através da construção da sua legitimação. É válido ressaltar que tal perspectiva está ancorada sob o plano do enunciado.

A análise da relevância dos temas pautados/enquadramento da notícia:

Cada jornal dispõe de uma espécie de agenda na qual deve apresentar diariamente ao público. Contudo, discorda-se aqui que os jornais televisivos tenham uma homogeneização dos conteúdos (VERÓN, 1985). A criação dos enquadramentos das notícias e das seleções e omissões de acontecimentos dizem sobre o modo como o programa pensa o país e, desse modo, cria o seu ponto de vista (JOST, 1998). Como o Jornal da Record se distingue do JN em relação ao seu posicionamento sobre os fatos que dizem respeito ao Brasil?

A análise do modo de acessar as principais fontes de cada noticia:

O discurso jornalístico não se legitima por si só (JENSEN, 1986) ele precisa buscar interdiscursividade com outros tipos de discurso, a exemplo do político e do acesso aos especialistas. Como os telejornais em referência legitimam o seu discurso e buscam diferenciar-se dos demais? 


\section{A análise da capacidade de interferir na agenda midiática $e$ na agenda política:}

Os telejornais utilizam como estratégias de distinção a sua capacidade de intervenção na agenda midiática. Geralmente, isso poderá ser observado tanto na análise das notícias veiculadas, pelos telejornais, como também a partir da análise dos dados secundários como a crítica sobre televisão publicada nas principais revistas semanais brasileiras.

\section{Pathos: estratégias de distinção do discurso da informação} sob a sedução

Nesta lógica do Pathos é preciso observar as estratégias de distinção através da construção da sedução. É válido ressaltar que tal perspectiva está baseada nas relações de construção de afetividade sob os plano da enunciação e do enunciado.

\section{A análise da construção discursiva da interação com o espectador (cena de enunciação, contato e formas de se dirigir ao espectador):}

Através de uma análise do texto verbal, da cena de enunciação criada e do modo como o apresentador se dirige ao público, pretendese observar a distinção do Jornal Nacional e do Jornal da Record em relação ao modo como seduz e cria a confiança do seu público.

A análise do strip-tease da noticia (forma de apresentar as noticias e seduzir o espectador):

Inspirado no critério da brevidade, no qual, nas palavras de Golding-Elliot (1979), 'as notícias devem ser como saias de mulher: longas o bastante para cobrir o essencial, mas suficientemente curtas para chamar a atenção'. Aqui pode ser percebida uma característica do discurso da informação que também está presente nas estratégias de distinção de uma marca: a sedução. O texto jornalístico deve chamar a atenção do leitor e seduzi-lo até o fim da reportagem, para os telejornais das $20 \mathrm{~h}$ é almejado, na lógica de funcionamento do produto, que o 
espectador assista-o do começo até o fim e não mude de canal para assistir ao seu concorrente.

Análise das estratégias de início e término do programa horário na Grade de programação da emissora:

Pontualidade e assiduidade nos horários de exibição dos programas jornalísticos ajudam a manter fiel o espectador.

A partir dessa proposta apresentada, pretende-se observar as estratégias de distinção da imagem da marca do discurso da informação utilizadas pelos canais em referência, a partir daqueles três grandes quadros gerais: Ethos, Logos e Pathos, e suas respectivas variáveis, já apresentadas. Juntos, estes três conceitos formam o circulo de estratégia de distinção do canal.

Se, por um lado, existe a promessa do canal através do seu círculo de estratégia de distinção do canal, o público, por outro lado, deve crer no seu cumprimento. Mas como isso pode ser possível? E quais as implicações deste cenário de disputa na esfera pública midiática?

Promessa e confiança: o papel dos suportes mídiáticos como dispositivos de confiança no espaço público e suas estratégias de distinção.

Vive-se em uma sociedade na qual existe uma quantidade exacerbada de acontecimentos e savoir-faires na qual é impossível estar à parte de todas estas discussões e saberes que transitam na esfera pública. Louis Quéré (2005) observa esta incapacidade humana de acompanhar todos os debates e problemas que transitam nesta arena de discussão pública.

Nós não podemos mais ser testemunhas de tudo que se passa no mundo. Nós não podemos mais ser competente em todos os domínios do saber, da técnica, da cultura, ou do direito (tradução nossa). (QUÉRÉ, 2005, p. 188).

Entretanto, há instituições cujo modus operandi vai ao encontro desta incapacidade de "tudo saber". Estas instituições, segundo Quéré (2005, p.188), efetuam o controle, a verificação e participam destes debates em nosso nome. Dito isso, o papel da mídia, e, especificamente 
do jornalismo, é decisivo em um espaço público democrático. Assim, a mídia é identificada por Quéré (2005) como um "dispositivo de confiança" que faz a mediação entre o público e o espaço público. Aos espectadores - que não dispõe de todos os saberes e dos conteúdos que circulam na arena pública - resta confiar no cumprimento do papel desenvolvido por essas instituições.

Contudo, a confiança não é um conceito isolado. Sua existência é possivel porque existe no espaço público a noção de desconfiança (Quéré, 2005). Assim, as pessoas são bombardeadas diariamente por informações sobre os mais diversos assuntos, mas este contexto não conduz a sociedade a uma situação de confiança. Segundo Quéré:

As midias representaram os suportes essenciais da arquitetura institucional das democracias modernas, entre muitas outras contribuições, a organização e ao funcionamento da sociedade. Elas não fazem mais do que se beneficiarem delas mesmas e da confiança dos seus públicos. Este é um caso de confiança em uma instituição (tradução nossa) (Quéré, 2005, p. 210).

No mecanismo de funcionamento da mídia (concorrência de mercado e política) está implícita a idéia da desconfiança, esta palavrachave que faz possivel existir a confiança. Como o público pode ter confiança na mídia, uma instituição mista: ora com finalidade privada, ora não? As midias ' (...) informam, educam, divertem etc., tudo para tentar ganhar dinheiro. É dificil saber que papel elas privilegiam' (tradução nossa) (Quéré, 2005, p. 211).

Pensar a televisão e sua lógica de funcionamento é oportuno porque se existe a "ditadura da imagem", na qual no jargão do senso comum "uma imagem fala mais do que mil palavras", poder-se-ia pensar que este dispositivo é mais credivel. Contudo, esta afirmação é falsa. Cada canal de televisão, através dos seus produtos midiáticos, constrói, diariamente, pontos de vista e distintos modos de apreensão da realidade. Esta é uma das caracteristicas do cenário de disputa midiático.

É por isso que nesta proposta não se acredita, somente, na ordem da enunciação (as maneiras de dizer), é preciso observar também os conteúdos midiáticos, isto é, a ordem do dito (enunciado). É preciso, pois, observar as particularidades de cada suporte e as suas características de distinção. A diferença, segundo Quéré pode ser uma forma possivel para observar este espaço de disputa pela confiança no 
espaço público mediatizado. E a ação do público neste espaço marcado pela confiança/desconfiança é crucial.

Uma outra maneira de argumentar seria considerar que o público deveria saber examinar, verificar, julgar por ele mesmo, avaliar e criticar. Mas esta é uma solução realista? Como assegurar uma participação permanente do publico? (Quéré, 2005, p. 215).

Os estudos sobre recepção identificaram este caráter não-passivo da audiência que Quéré (2005) questiona, entretanto, não se tem ainda a resposta sobre como tornar efetiva a participação política do público sobre o conteúdo midiático. No Brasil, o projeto de construção de uma rede de TV pública está sendo desenvolvido pelo governo atual e prevê a participação tanto do Estado como também dos cidadãos neste processo.

Na proposta de análise aqui apresentada, aceita-se o desafio de observar a construção discursiva das estratégias de diferenciação desenvolvidas pelos canais de televisão nos seus produtos midiáticos.

108 Neste estudo o objeto escolhido é o cenário de disputa entre os tradicionais telejornais brasileiros das $20 \mathrm{~h}$. Assim, analisar suas estratégias de distinção é também fazer um esforço para compreender esta sociedade, também denominada "sociedade da informação", e os seus inúmeros discursos e arenas de disputa que estão presentes no espaço público midiático.

\section{Notas}

${ }^{1}$ Ressalta-se a pesquisa que vem sendo realizada pela Prof.a. Dr.a Maria Carmem Jacob de Souza (2003) sobre os sentidos produzidos nas telenovelas brasileiras dos anos 90 , exibidas após o Jornal Nacional, pela TV Globo.

${ }^{2}$ Entende-se por chamada os pequenos anúncios nos quais as emissoras divulgam os seus programas antes de serem veiculados. Essas chamadas podem estar presentes tanto nos intervalos comerciais, como também no final dos programas.

${ }^{3}$ Segundo pesquisa Ibope divulgada em 28.02 .07 ,o Jornal Nacional, dispõe de 33 pontos de audiência contra 10 pontos do Jornal da Record. Um outro dado importante divulgado nesta mesma pesquisa é a 
manutenção da liderança da Rede Globo (20 pontos), responsável pela exibição do Jornal nacional, e uma mudança no segundo lugar da emissora do SBT, para a TV Record (07 pontos). Esta emissora exibe o Jornal da Record.

${ }^{4}$ Este estudo é uma pesquisa de doutorado desenvolvida no PÓSCOM/ UFBA que pretende identificar a identidade de marca de dois enunciadores do cenário midiático brasileiro, que para os fins deste estudo são dois canais de televisão: A TV Globo e a TV Record. A démarche escolhida é a análise do discurso da informação, mundo real (JOST, 1999), destes dois canais. Para tanto, almeja-se observar as estratégias de distinçâo utilizadas pelos dois telejornais brasileiros líderes de audiência, no horário nobre: o Jornal Nacional e o Jornal da Record, por se tratarem dos dois "gêneros puros" do discurso da informação, conforme já foi comentado neste artigo.

'É válido salientar o trabalho que vem sendo desenvolvido pelo grupo de análise de telejornais do PÓSCOM/UFBA sobre os "modos de endereçamento" dos programas jornalísticos da televisão brasileira, coordenado pela Prof.a Dr.a. Itania Gomes. Para um maior aprofundamento do trabalho do grupo vide Gomes (2003; 2005).

\section{Referências}

BAKHTIN, Mikhail. Marxismo e Filosofia da Linguagem. Trad. de Michel Lahud e Yara Frateschi Vieira, 10", São Paulo: Hucitec, 2002, 196p.;

CASETI, Francesco ; Odin Roger. De la paléo- à la néo-télévision. Approche sémio-pragmatique. Communications. n. 51. Paris : Seuil, 1990.

CHAMBAT-HOUILLON, Marie-France. Une télévision ou des chaînes ? L'identité de la troisième chaîne couleur. In: JOST, François. Années 70, la télévision en jeux. Paris: CNRS éditions, 2005.

série policière. $\mathrm{s} / \mathrm{d}$ L'auteur au programme. Etude des bandes-annonces d'une CHARAUDEAU, P. ; MAINGUENEAU, D. Dicionário de análise do discurso. São Paulo: Contexto, 2004.

ECO, Umberto. Têvê : A transparência perdida. In : Viagens

na irrealidade cotidiana. Rio de Janeiro : Nova Fornteira, 1989. 
FLOCH, Jean-Marie. Sémiotique, marketing et communication. Sous les signes, les stratégies. Paris : Presses Universitaires de France, 1990. . Le changement de formule d'un quotidien approche d'une double exigence : la modernité du discours et la fidélité du lectorat. Les Medias - Expériences recherches actuelles applications. Paris: IREP, 1985

GOMES, Itania Maria Mota et alii. "Modo de Endereçamento no Telejornalismo do Horário Nobre Brasileiro: o Jornal Nacional, da Rede Globo de Televisão". Trabalho apresentado ao NP 07 - Comunicação Audiovisual, no XXVIII Congresso Brasileiro de Ciências da Comunicação - Intercom, Rio de Janeiro, 2005; . "Quem o Jornal do SBT pensa que somos? Modos de endereçamento no telejornalismo show" in Revista FAMECOS: mídia,

cultura e tecnologia. Porto Alegre: Edipucrs, no. 25 , dez/2004, p. $85-$ 98;

. Das utilidades do conceito de modo de endereçamento para análise do telejornalismo. In Elizabeth Bastos Duarte \& Maria Lília 110 Dias de Castro (Orgs.) Televisão: entre o mercado e a academia. Porto Alegre: Ed. Sulina, 2006;

JENSEN, K. B. Making sense of the news. Towards a theory and an empirical model of reception for the study of mass communication. Copenhague: Aarhus University Press, 1986.

JOST, François. Comprendre la télévision. Paris: Armand Colin, 2005 . Seis lições sobre televisão. Porto Alegre: Sulina, 2004.

. Introduction à l'analyse de la télévision. Paris : Elipses 1999. . Quand y a-t-il énonciation télévisuelle? In: BOURDON, Jérôme; JOST, François. Penser la télévision. Actes du colloque de Cerisy. Paris: Armand Colin, 1998.

LOCHARD, Guy. L'information télévisée. Mutations professionnelles et enjeux citoyens. Vuibert : Paris, 2005. p.33-44 219 p. MARTIN-BARBERO, Jesús. Dos meios às mediações. Comunicação, cultura e hegemonia. Trad. Ronald Polito e Sérgio Alcides. 2a ${ }^{\text {a }}$ Ed. Rio de Janeiro: UFRJ, 2001.

QUÉRÉ, Louis. Les « dispositifs de confiance » dans l'espace public. Reseaux, n. 132, Paris: FTR\&D Lavoisier, 2005. 
RICOEUR, Paul. De la rhétorique à la poétique. In :

Anthologie. Paris : Seuil, 2007.

SEMPRINI, Andrea. El marketing de la marca. Una aproximación semiótica. Barcelona: Paidós, 1992.

SOUZA, Maria Carmem Jacob. A construção social de sentidos e o fenômeno da recepção: em questão o papel dos realizadores. Famecos, n. 20. Porto Alegre, 2003.

TUCHMAN, Gaye. [1978]. Making News. A study in the construction of reality. Londres, Free Press, 2002.

A objectividade como ritual estratégico: uma análise das noções

de objectividade dos jornalistas. In: TRAQUINA, Nelson (org). Jornalismo: questões, teorias e 'estórias'. Lisboa: Veja, 1993.

VERON, Eliseo. El semiose social. Barcelona: Gedisa, 1987. . Quand lire, c'esr faire: 1 énonciation dans le discours de la presse écrite. Semiotique II. Paris: IREP, 1985. . L'analyse du "contrat de lecture" : une nouvele methode pour les

etudes de positionnement des supports presse. Paris: IREP, 1985. . Il est là, je le vois, il me parle. Communications. n. 38. Paris, 1983

WOLF, Mauro. Teorias das comunicações de massa. São Paulo: Martins Fontes, 2005. 
